\title{
Questions and Countermeasures of Pension Agencies in Rural Areas under the Equality in Constitution
}

\author{
Yan Gong \\ School of Law \\ Sichuan University \\ Chengdu, China 610207
}

\begin{abstract}
During the development of rural pension agencies in rural areas in China, it has to face series of problems as inadequate security in law and policy, poor infrastructures and lack of professional nurses. Seen from the equality in constitution, the irrational division between the systems for urban and rural pension agencies and the failure to carry out rational differential treatment to the urban and rural pension agencies are main reasons leading to the problems mentioned above. Accordingly it needs to abolish the irrational division in urban and rural areas in legislation so as to promote equality in form, build a legal policy system preferential to protect the pension agencies in rural areas in order to achieve substantial equality as well as establish and improve the supervision and supporting mechanism for the pension agencies in the rural areas.
\end{abstract}

Keywords-rural area; pension agency; formal equality; substantive equality

\section{INTRODUCTION}

With the acceleration of the aging population in China, the pension service, as a basic public service, has become a focus for national laws and policies. The "13th Five-Year Plan" promulgated in 2015 pointed out that the development of pension policies in China shall aim at "building a multi-level pension service system with family pension as base, retirement community as dependence and agencies as supplement". In the rural areas where the aging problem is in a much serious situation than the rural areas, in recent years, the pension agencies, which have made rapid progress, have become an indispensable pension model in the pension service system in rural areas. However, frequent accidents such as fires happened in Heilongjiang Hailun Lianhe Nursing Home and Henan Lushan Nursing Home have exposed a series of problems in pension agencies in the rural areas. Main reasons for the problems are the unbalanced development under the urban and rural structures. Therefore, this article aims to analyze main reasons of the problems concerning the pension agencies in rural areas and explore solutions applicable, which will be of great significance to promote the healthy operation and long-term development of the pension agencies in rural areas.

\section{Main Problems The Pension Agencies Face In The COUNTRY}

The aged population in China ranks No.1 around the

Funds Project: China Law Society 2015 Ministerial-Level Law Research Topic Study on the Construction of Legal Service System and Implementation in Poor Rural Areas of Southwest Ethnic Minorities. Author: Gong Yan, ethic Han, (1973-), native of Yanting, Sichuan Province, PhD graduate, School of Law, Sichuan University, lecturer of Shanxi Normal University, research orientation: constitution and law of human rights world, compared with urban areas, the aging problem is much more serious in rural areas. During the "Fifth population census" in 2000 , the proportion of the population aged 60 or more was $9.7 \%$ in urban areas and $10.9 \%$ in rural areas. During the "Sixth population census" ten year later, the proportion of the population aged 60 or more reached $11.7 \%$ in urban areas and 15\% in rural areas. [1] Meanwhile, with the acceleration of the aging population and urbanization, the aged empty nest and empty nest-like families grew rapidly in rural areas across the country, which, by 2006 , had reached $48.9 \%$ of the aged families in total.[2] The above shows that the traditional family pension mode has been unable to independently deal with the increasingly serious pension problem in rural areas, it is in an urgent need for social and professional pension models as pension agencies. In recent years, the state focuses on the development of the pension service, under the background that policies are promulgated to support social forces in the establishment of pension agencies, the pension agencies made a rapid progress. From 2010 to 2012 , the number of pension agencies in rural areas was in an upward trend, [3] as of 2013, there were 7077 pension agencies in urban areas, 30,247 pension agencies in rural areas.[4] However, with the increased number of pension agencies in rural areas, a series of problems have appeared, which are inflected in the following:

\section{A. Inadequate Policies for Security and Space Blocked for Development}

Under the policy-based rules and systems for the pension service, the policies advocating pension agencies are more than laws in rural areas, and there are no operable regulations and rigid rules for the positioning, establishment and operation of pension agencies in rural areas. Besides, in the existing laws and policy systems concerning the pension service, on the one hand, little attentions are paid to the pension agencies in rural areas, and there are no special laws or policies from central to local to regulate the pension agencies in rural areas. From 1978 to 2014, forty seven laws and regulations were promulgated for pension agencies by the central government in the country, and only five laws and policies were released for the pension agencies in rural areas such as "Rules for Pension Service of Five Guarantees in Rural Areas", "Interim Measures for Nursing Home Management in Rural Areas" and so on. [5] On the other hand, the existing laws and policies concerning the pension services in rural areas are imperfect. In 2010, the Ministry of Civil 
Affairs promulgated the "Administrative Measures on Pension Service Agencies of Five Guarantees in Rural Areas", but it did not apply to all types of pension agencies in rural areas; the local rules and regulations mainly focused on the rural endowment insurance. Due to the lack of support of mature laws and policies, the pension agencies in rural areas have the development space blocked, whose prospective is worrying.

\section{B. Poor Infrastructures, with Security Risks and Accident Incentives}

As far as the hardware facilities, the pension agencies in rural areas run out of standards, house of some agencies receive no supervision in quality security; besides, there are no adequate fire facilities and no fire permits needed, thus there are higher security risk, which are easy to cause accidents. May 25, 2015, fire broke at Kangleyuan Apartment for the Aged, Sanlihe Village, Lushan County, Pingdingshan City, Henan Province, killing 38 people. The investigation showed, the apartments on fire were built with color pre-coated steel plates which were prohibited for buildings of pension agencies in the country, besides, the fire facilities inside failed to meet standards either. On the other hand, the pension agencies in rural areas generally have no medical conditions. The combination of medical care and pension should be one of the development trends for the pension agencies. The lack of medical conditions will low the capabilities of the pension agencies to cope with sudden illnesses and unexpected accidents. However, within the pension agencies in the country, the proportion of pension agencies with five guarantees in rural areas reaches $41.7 \%$ only and $22.3 \%$ have no separate medical rooms or professional nurses, the situation in rural areas is much more serious. [6]

\section{Lack of Professional Nurses and Restriction to Improve the Service Quality}

Adequate qualified professional nurses are soft power of pension agencies, which determine the service quality and upgrade of the pension agencies. On the one hand, the proportion of nurses is improper in most pension agencies in the country, especially it is much serious in rural areas. The "Guiding Opinions of the Ministry of Civil Affairs on the Construction of Rural Five-Guarantee Service Agencies" points out that in principle, the ratio between staffs to the aged should not be lower than 1:10. However, according to statistics, only one nurse is arranged for 13 of the aged averagely in the pension agencies of five guarantees in rural areas in the country [7] The field surveys at the non-governmental pension agencies in rural areas show, that proportion between nurses and the aged fails to meet standards, and it is in a general lack of professional and non-professional nurses. On the other hand, there are no professional trainings conducted regularly, besides, the poor quality of professional nurses is also an important problem troubling the pension agencies in rural areas for a long time. Surveys show that the nurses of pension agencies in rural areas are mostly at the age of $40-50$ or in layoff, who generally have higher ages but lower culture, most receive simple training only, the professional level is lower and the service is far to reach standards. [8]

\section{Lack of Governmental Supervision and Industrial Standards, Overall Service Level Low}

Article 5 of the "Interim Measures for the Administration on Social Welfare Institutions" provides that the department of civil affairs under the above-county level people's government shall be competent department of social welfare institutions and take charge of relevant management, supervision and inspection. Survey data at non-governmental pension agencies in some towns and villages show that the management in the pension agencies have never heard of the supervision and evaluation system for non-governmental pension agencies in towns and villages, and the routine inspection of the competent departments just stays in the form, and only oral advices are made against problems arising or no punishment is done as required. [9] In addition, the standardization of pension service is still in progress in the country, and it has no standards for classification and service for pension agencies, and the pension agencies in rural areas are in a poor development due to the lack of drive to the social and economic development inside and inefficient supervision outside as well as the lack of service quality evaluation systems. A large number of studies have shown that the pension agencies in rural areas have a big gap with that of urban areas, and it is known to all that the overall service level is lower.

\section{ANALYSIS OF PROBLEMS EXISTING IN THE PENSION AGENCIES IN THE COUNTRY From THE EQUALITY IN CONSTITUTION}

For the pension agencies, the amount and quality of pension resources owned are fundamental factors affecting the service quality and development level. Obviously the problems of laws, infrastructure and professionals related to the pension agencies in rural areas have direct relations with the poor pension resources as laws, policies, capitals, lands and manpower needed for the development of the pension agencies. It is true that the poor economy and inadequate resources in rural areas have close relations to the natural environment and the production efficiency of agriculture falling behind that of industries. But it must be pointed out that in social resources, institutional resources are in a position of foundation and core, which determine the possession, use and earnings of the people in material resources. There is an institutional factor that can not be ignored for the poor development of pension agencies in rural areas, namely the dualistic structure system between urban and rural areas, which originated in the early days of the foundation of New China, and still exists up to now. Therefore, in the opinion of the author, there are many reasons causing the above-mentioned problems in pension agencies in rural areas, yet the anomie of the equality in constitution over the balanced development of pension agencies in urban and rural areas is the key reason for the abnormal development of pension agencies in rural areas.

\section{A. Irrational Institutional Division between Urban and Rural Pension Agencies under the Background of Urban-Rural Dualistic Structure}

Starting from the modern times, equality, as an important value goal of laws, has become a basic content of the 
constitution in most countries. Article 33-2 of the Constitution in China stipulates that "all citizens of the People's Republic of China are equal before the law", thus the equality becomes one of the basic principles for laws in the country, it requires that all citizens will be protected equally regardless of gender, ethic group, religion, occupation, social status, property status and place of residence. The equality refers firstly to the formal equality, that is, the same treatment will be given under the same situation in the same matter, it is prohibited to discriminate irrationally. The formal equality is a basic point, and also a premise and base, it requires that when establishing laws and policies, the state should provide equal protection to individuals and matters with the same abstract properties, but no division due to specific differences [10].

As we all know, in order to achieve the goal for prior development of the heavy industry at the beginning of the foundation of the P. R. China, an unbalanced economic development mode, where the agriculture served the industry and rural areas served the cities, was formed. During the course, the funds were withdrawn out of agricultural income to support the industrial construction and accumulation, i.e. from the beginning of the foundation to the opening-up and reform, more than half of the agricultural output were withdrawn for the industrial construction; Furthermore, from the opening-up and reform to 1994, the funds that rural areas contributed to the cities were 5.3 times of that before the reform[11]. Meanwhile, in order to facilitate the effective implementation of the above-mentioned economic strategy, the state made a series of institutional arrangements related to the urban and rural division, i.e. "Regulations on Household Registration of People's Republic of China" released in 1958, which was a symbol for the division of urban and rural household registration in the system, and the system-based housing, health care, employment, education, pension and other welfare systems for urban residents only. Though the irrational division between the urban and rural systems above-mentioned was a necessity at that time, yet it deviated from the equality tenet of the constitution, which caused the preference to social resources and to cities and industries and the irrational distribution of urban-rural resources, as a result, the rural areas, due to poor economic basis, develop slowly and fall behind the cities.

Under the background of the urban-rural dualistic structure, it also forms a historical practice, based on which, laws and policies make an irrational division on urban and rural pension agencies. On the one hand, there is a history of irrational division on urban and rural pension service in laws and policies in the country. From the foundation of P.R. China up to 1994, there were 16 laws and policies concerning the urban pension, covering the objects concerned, retirement age, pension and so on, yet in the same period there were only 4 laws and policies concerning the rural pension, most of which were the principled provisions, difficult for operation.[12] On the other hand, some of the central and local laws and policies concerning the pension aim at urban pension services only or clearly define "urban priority." i.e. the "Code of Architectural Design for the Elderly" provides that it applies to the design of urban construction, expansion and rebuilding of residential buildings and public building for the for the elderly; "Notice of Ministry of Civil Affairs on the Reform Pilot of Public Pension Agencies" points out that it will give priority to the public pension agencies under departments of civil affairs at big and medium-sized cities for pilot service. As far as the local laws and policies concerning the pension, the "Measures for the Administration on Pension Agencies in Qingdao" provides that it applies to the pension agencies established in the administrative areas of this city, yet the nursing homes in towns and villages still follow the rules of nursing homes in rural areas.

In a word, under the historical background where the earnings of villages and agriculture were withdrawn for the cities and industry, which have caused a dualistic structure, namely the poor economy in rural areas, the distribution of urban and rural resources is irrational, besides, the irrational institutional division on the urban and rural pension agencies continues, as a result, the pension agencies in rural areas face the lack of resources as what mentioned above, and the development of the urban and rural pension agencies is in a serious imbalance.

\section{B. Failure to Carry out Rational Differential Treatment to the Urban and Rural Pension Agencies in Face of the Difference in Resources and Inequality}

The formal equality refers to an equal treatment before equal chances according to individuals and the same abstract properties of specific matters. Yet, the equality, without considering the difference of individuals and matters must cause an inequality in reality, which forms a polarized situation where the strong one will be stronger, the weak one will be weaker. In view of this result, a theory of substantive equality is defined in modern constitutions as the following: reasonable difference treatment should be provided for different circumstances and different matters. And the equality in the Constitution is a unity of formal equality and substantive equality. The formal equality is the base and prerequisite, while the substantive equality is an amendment and supplement to the formal equality [13]. The substantive equality requires that stage laws and policies should provide reasonable differential treatment for different individual and matters in order to achieve the substantive equality.

As what mentioned above, at the beginning of the foundation of the P. R. China, farmers paid agricultural taxes and agricultural tax-based fees so as to contribute to national construction. According to the statistics of the Ministry of Agriculture in 1992, the average cost borne by farmers was 200 yuan, totaling over 150 billion yuan;[14] from 1994 to 1997, the average taxes and fees paid directly to the state were 9 times of that in 1990-1993, [15] which changed gradually until the reform of rural taxes and fees starting in 2000 and finally ended with the abolishment of the "Regulations of the P. R. China on Agricultural Taxes" in 2006. On the contrary, the farmers who were engaged in agricultural production and have reached ages of pension today together with the urban workers and cadres of the same time both have made the same contributions to the country, but the pension conditions for the two are different completely. Mar 4, 2016, the "China Longitudinal Aging Social Survey (CLASS) Report" released by the Gerontics Institute, Renmin University of China 
pointed out that $91.25 \%$ of the elderly in urban areas received pension, $20.46 \%$ higher than that in rural areas. Meanwhile, according to the report data, the pension of government institutions and public institutions is 50 times of than in rural areas; China's aging research topic group made surveys on the population of the aged respectively in 2000, 2006 and 2010, and found that the pension agencies in rural areas fell obviously behind that in urban areas in medical equipment, starting points for care support for the disabled elders, long term professional service and so on. Seen from the above, it is legal on the constitution that reasonable differential treatment should be provided to urban and rural pension agencies, namely the pension agencies in rural areas, which have little pension resources and fall behind in the development, should be supported; and it is rational seen from the social fairness; and it is urgent from the actual demands.

However, existing laws and policies only focus on modifying the formal inequality caused by the urban-rural dualistic structure, namely it aims at the coordinated development of the urban and rural pension service, but ignores the resource difference in the urban and rural pension agencies and the inequality in development, many more laws and policies are established for the cities, which are unsuitable for the actual operation of rural pension agencies. Meanwhile, there are no efficient preferential measures for the pension agencies in rural areas, and the existing policies to support the pension agencies in rural areas are mostly declaratory provisions which are unsuitable for operation and in the lack of substantive significance, i.e. The "Several Opinions of the State Council on Accelerating the Development of Pension Service" points out that the financial funds for pension service of governments at all levels should give priority to the rural areas, but there are no clear provisions for preference, so it is difficult for practice. In addition, preferential policies for pension agencies in rural areas are far to be implemented. The "Opinions of Accelerating the Socialization of Social Welfare", the "Opinions of Accelerating the Development of Pension Service" and so on point out that the state should give preferential policies support for the pension agencies established by social forces in investment, financing, land supply, tax, subsidies and so on. However, the surveys from local areas found that the preferential and support policies were not effectively implemented in rural areas, for example, in the pension agencies in rural areas, Shandong Province, preferential policies and measures as public support for non-governmental units, non-governmental operation for public establishment were not implemented or practiced in most areas;[16] in rural areas, Jiangsu Province, land supply, water, power distribution, sanitation, network and cabled television were restricted by the industry, and the pension agencies enjoyed no any preferential policies. [17]

In summary, facing the irrational institutional division which cause the resource difference and the inequality in development of urban and rural pension agencies, the state fails to give reasonable differential treatment to the urban and rural pension agencies, and fails to correct the inequality formed in the urban and rural pension agencies, which have aggravated the irrational allocation of resources between urban and rural pension agencies and more serious inequality in development, and the problems that rural pension agencies face become more serious.

\section{MEASURES To Promote The DEVELOPMENT OF PEnsion AgEnCIES In RuRAL AREAS IN THE COUNTRY ON THE BASIS OF EQUALITY IN CONSTITUTION.}

\section{A. Abolish the Irrational Urban-Rural Division in Legislation to Promote the Formal Equality}

The equality design in legislation is the base and prerequisite to realize the equality in the constitution. The legislative idea should abide by the principle of equality, abolish the irrational urban and rural division, eliminate the laws and policies blocking the development of pension agencies in rural areas, set a law position for the equal development of urban and rural pension agencies and make them enjoy the same chance for equal development. The laws and policies released by the central government should clearly indicate the equal treatment for pension agencies of all types and in all areas in order for a balanced development, and it will be a guiding thought for the laws and policies of the coming and local pension service. For example, the "Layout for Social Pension Service System Construction (2011-2015)" and the "Several Opinions of the State Council on Accelerating the Development of Pension Service" point out respectively that there was an unbalanced development in the urban and rural pension service in the country, and the latter even took the "coordinating the urban and rural pension resources to promote the balanced development of basic pension service" as a basic principle; the suggestions of the CPC Central Committee on the "13th Five-Year Plan" took the coordination as a basic concept, and clearly pointed out, promote the coordinated development of urban and rural areas, insist on the industry back feeding the agriculture, urban areas support for rural areas, promote balanced allocation of urban and rural public resources and make basic public services equal for all.

\section{B. Build the Preference to Protect Laws and Policies of Pension Agencies in Rural Areas for Substantive Equality}

The irrational division of urban and rural systems has led to the lack of institutional resources in pension agencies in rural areas, it needs to build a comprehensive multilevel law and policy system for pension agencies in rural areas. The central and local pension laws and policies should contain commonly used laws and policies which are applicable for all pension agencies and pay special attentions to the pension agencies in rural areas. For example, the "Regulations to Promote Pension Service in Qingdao" gives special provisions to the layout, construction, service supervision, support and security related to the pension service in rural areas. Meanwhile, there should be special laws and policies applicable for pension agencies in rural areas such as "Measures to Manage Pension Service Agencies of Give Guarantees in Rural Areas". Besides, in order to realize the system and legalization for the pension service in rural areas, the policy documents of pension service regulation shall be transformed gradually into laws, strengthen the legal protection for the development of pension agencies in rural areas and make the pension agencies in rural areas own the same law environment as the pension agencies in urban areas. 
In view of the weak position in resources of rural pension agencies in rural areas and the unbalanced development with the urban pension agencies due to historical reasons, establish clear, operable and efficient preferential measures to promote the development of pension agencies in rural areas so as to the pension of farmers and the development of pension agencies. For example, as what mentioned above, for the farmers who have made contributions to the country the same as urban cities since the foundation of the country are in an unequal position in pension treatment, if the family pension is inapplicable, they can be integrated to the institutional pension through subsidies given to pension agencies in rural areas as per ages, which can not only correct the unequal treatment in urban and rural pension treatment but also support the development of pension agencies in rural areas. In addition, it needs to establish a mechanism to carry out the preferential policies for pension agencies in rural areas. On the one hand, take measures to promote the implementation preferential policies for pension agencies in rural areas, which shall be introduced to the government affairs; strengthen the publicity of preferential policies of pension service planning and pension agencies in rural areas through more forms; promote the public awareness of the above policies so as to lay a thought foundation for the implementation of preferential policies. On the other hand, subdivide preferential policies for pension agencies in rural areas, form corresponding implementation details or methods to make it operational; set up special supervision departments to monitor and check the implementation of preferential policies or establish preferential policies report systems, and integrate them into the department's performance evaluation system so as to strengthen the policy implementation.

\section{Establish and Improve Supervision and Supporting \\ Mechanisms for the Pension Agencies in Rural Areas}

In order to promote the healthy development of pension agencies, it needs to strengthen the safety supervision and risk management over the pension agencies. Therefore, on the one hand, perfect the supervision-related laws and regulations for the pension agencies in rural areas, make clear the supervision executer, supervision content, supervision procedure and punishment of illegal acts, so as to provide laws reference for the routine supervision on the establishment and operation of pension agencies in rural areas; on the other hand, change the management model of regarding access but ignoring supervision, strengthen the supervision of pension agencies in operation, and build a supervision mechanism for pension agencies in rural areas characterized of beforehand review and supervision, middle and after supervision according to law.

Based on the actual situation in rural areas, build a mechanism benefiting the equal development of pension agencies in rural areas. Relying on the governmental support to pension agencies in land, capital and talents, it also needs to develop a service resource development mechanism suitable for the pension agencies in rural areas. Main experience include: Hubei Enshi Tujia Autonomous Region developed a circular economy in welfare institutions, Chongqing Fengdu County Civil Affairs Bureau developed office economy, which eased the shortage of funds in welfare institutions in rural areas; Heilongjiang introduced gradually the pension service into the rural labor transfer training, and guided social training institutions and personnel to participate in pension service training. [18] meanwhile, actively promoted the combination of nursing and medical area in the pension agencies in rural areas. "China's aging research topic group" thinks that the combination pension and medical area mode can be diversified, medical room or health rooms, or rehabilitation hospital, nursing homes can be set in pension agencies, and it may establish cooperation with medical institutions around [19]. Guided by this direction, according to the actual conditions of medical resources in rural areas, it may establish a mode of combination of medical care and pension in the pension agencies in rural areas.

\section{CONCLUSION}

The pension agencies in rural areas, compared with that in urban areas, are in a poor development throughout the country, and a lot of problems can be found in laws, policies, infrastructure and caregivers and the like. The deep-seated reason is the irrational institutional division between urban and rural pension agencies under the background of urban-rural dualistic structure, furthermore, rational and distinct approaches failed to be adopted according to the actual differences in development of the urban and rural pension agencies. In order to find a solution for the imbalanced development of urban and rural pension agencies and promote the well going of rural pension agencies, it needs to observe the equality in constitution in legislation and push the formal equality and substantive equality; in the meanwhile, successful experience can be borrowed to set up and perfect a supervision and supporting mechanism in favor of the development of rural pension agencies.

\section{REFERENCES}

[1] Tang Jun, Digital Truth of Aging Population, County Economy Report in China, Vol. 003, Sep 3, 2015.

[2] Surveys on the Elders in Nationwide Empty Nest and Empty Nest-like Families in Rural Areas Research Topic Group: Surveys on the Elders in Nationwide Empty Nest and Semi-Empty Nest Families in Rural Areas, China Social Work, Vol. 5, 2009

[3] Department of Rural Social and Economic Survey of National Bureau of Statistics of the P.R. China: China Rural Statistics Yearbook-2014, Beijing: China Statistics Press, Version 2014, pp 284.

[4] Department of Social Science and Cultural Industry of National Bureau of Statistics of the P.R. China: China Social Statistics Yearbook-2014, Beijing: China Statistics Press, Version 2014, pp 74.

[5] Zhang Zaiyun, From Management to Rules: Historical Courses of Policies for Pension Agencies Supervision since the Foundation of New China, Scientific Research on Aging, Vol.1,2015, based on the law search system data of Beijing University

[6] China Scientific Research on Aging Topic Group: Study on the Disabled Elders across the Country, Disability Research, China Civil Affairs, Vol.2, 2011

[7] Luo Pingfei, Carry out the Spirits of The Fifth Plenary Session of the 17th Central Committee of the Communist and accelerate the Science Development of Five Guarantees for Rural Pension Work, China Civil Affairs Vol.1, 2011

[8] Institution of Population Research, Beijing University: Achievement Report of Research on Pension Service Work in Rural Areas, http://files2.mca.gov.cn/fss/201306/2013060308245833.pdf

[9] Wang Deqiang, Pan Simin, Study on Legal Problems Existing Non-Governmental Pension Agencies in Towns and Villages and 
Countermeasures, Based on Fields Surveys in Hanchuan, Hubei, Zhuhai, Guangdong, Journal of Huazhong Agricultural University (Social Sciences Edition, Vol.4, 2015

[10] Lin Laifan, Handout of Constitution, Beijing: Law Press China, Vol.2011, pp272-275

[11] Liu Zheng, Discussion on Why Are Chinese Farmers Poor for a Long Time, Negotiating with Prof Liu Ji, Exploration and Free Views, Vol.6, 2005

[12] Zhang Shiping, Liu Lihua, Historical Evaluation, Characteristics and Reasons of the Aged Security in Rural Areas Since the Foundation of the P.R. China, Population Journal, Vol.5, 2000

[13] same as [10].

[14] same as [11].

[15] Zhang Yixiong, Staged Decomposition and Analysis of Farmers' Burdens in New China, Researches In Chinese Economic History, Vol.3, 2004

[16] Wang Hongna, Analysis of Wills and Demands for the Elderly to Live in Social Pension Agencies in Shandong, Dongyue Tribune, Vol.9, 2011

[17] Yao Zhaoyu, Social Pension Service in Rural Areas: Mode, Mechanism and Development Course, Based on Surveys in Jiangsu Province, Gansu Social Sciences, Vol.1, 2014.

[18] same as [8]

[19] Wu Yushao, Wang Lili, et al, Study on Development of Pension Agencies in China, Scientific Research on Aging, Vol.8, 2015 